\title{
The Effectiveness of STEM Education for Overcoming Students' Misconceptions in High School Physics: Engineering Viewpoint
}

\author{
Uswatun Hasanah* \\ Department of Educational Development and Cultural and Regional Studies, Graduate School for International Development and Cooperation, \\ Hiroshima University, Higashi-Hiroshima City, Hiroshima, Japan
}

*Corresponding Author: uswatunhasanah216@yahoo.com

\section{ABSTRACT}

In the present study, an experimental teaching material using a soundcard oscilloscope developed for science, technology, engineering, and mathematics (STEM) education considering the engineering viewpoint was applied to address student's misconceptions in the alternating current (AC) circuit topic in high school physics. Four experiments were conducted, and 13 conceptual understanding questions were used to explore the concept of the AC circuit among 192 secondary school students in Indonesia. This study concluded that the STEM system used in this study was considered to be useful to overcome the various misconceptions in high school physics. As a result of this study, it is recommended that more researchers should find, create, develop, and implement more teaching materials that support the understanding of students in AC circuits as well as the other parts of physics. Deeper investigations into the pre-conceptions of students would be another area of research that this study identified as an area of the focus needed in investigating cases of misconceptions.

KEY WORDS: alternating current; misconceptions; soundcard oscilloscope; science, technology, engineering, and mathematics teaching materials

\section{INTRODUCTION}

0 ince 2005, Indonesia has been implementing a schoolbased curriculum. The school and teacher have the authority to decide the educational goals based on their own school's perspective. In other words, teachers have responsibility for: (1) Assembling and formulating the learning intention, (2) choosing and creating the teaching materials and tools based on the needs, interests, and the children's development that is supported using the various methods and teaching media, and (3) constructing the program to include assessment as well as feedback (Essays, 2018). However, teachers have found some difficulties in completing these tasks due to their students' views about physics. It has become an unattractive subject for many secondary school students. Both the complexity of equations and the need for students to be able to explain the concept have created a big challenge for teachers to support students' understanding, especially in topics such as electromagnetics. Electromagnetics has emerged as one of the most challenging topics in physics (Susilowati, 2006). In fact, hands-on activities are rarely implemented in these classes due to the lack of or inadequate apparatus to teach this topic (Marini, 2017).

Hands-on activities have become one of the key means to influence the achievement of the students (Sadi and Cakiroglu, 2011). Hands-on activities have been reported to help the student go through the concept, avoid misconception, understand the knowledge, and obtain the skill as well as the creative thinking (Djamal, 2013). Nowadays, misconceptions are getting more attention from researchers. To accommodate new ideas in a meaningful way and also to complete the conceptual domain, realigning, reorganizing, or replacing existing misconceptions are necessary (Chong et al., 2013; Leonard et al., 1996; Smith et al., 1999). Furthermore, research has highlighted the need for considering students' misconceptions during the development of curriculum, teachers' learning method, as well as the teaching materials (Kucukozer and Kocakulah, 2007; Putri et al., 2017).

The previous researchers have revealed that the misconceptions surrounding current electricity are nearly universal, resistance to change, and are even perpetuated by teachers, textbook, and collective experience (Duit et al., 1985; Shipstone et al., 1988). In most cases, even those students who seem to have a good understanding of basic direct current concepts and are able to apply them correctly in problem-solving tasks find it hard to grasp the concepts of alternating current (AC) (Biswas et al., 1998). Posner et al. (1982) proposed four conditions that must occur before students can replace an existing misconception:

1. Students must experience dissatisfaction with their existing conception;

2. They must be able to understand the new conception;

3. The new conception must seem plausible to them; and

4. The new conception must appear to be better at explaining their experiences and observations than their previous conception.

A learning process that can eliminate misconceptions and prevent the formation of these concepts should be used. Instead of applying traditional teaching methods in science education, 
teachers should provide space for students to reflect on their thinking by discussing with a partner or by reporting back to a group or class (Turgut et al., 2011). Therefore, well-designed hands-on activities are needed.

Furthermore, Honey et al. (2014) and Wendell and Rogers (2103) highlighted the existence of science, technology, engineering, and mathematics (STEM) education that offers multidisciplinary subject with innovative teaching materials. These materials not only attract students' interest but also provide the lesson with a deeper understanding, critical thinking, tool use, curriculum integration, and problem-solving that are indirectly connected to the conceptual knowledge and the alternative concepts of the students (Caliskan et al., 2010; Kolodner et al., 2003; Sutherland, 2002).

STEM education is known as not only an abbreviation of STEM but also as an interdisciplinary subject that does not limit the student's content knowledge in the class implementation or in their future career. It comes with three approaches: The silo approach, the embedded approach, and the integrated approach (Quang et al., 2015). In the silo approach, teachers coach individual STEM subject separately. Meanwhile, in integrated approach, the STEM content areas are mixed and learnt as one subject. The last approach, the embedded approach, has become the most common approach as this instruction tends to be more effective. This approach involves the use of engineering as a context for learning the science and mathematics and has better facilitates that connect between/ among multiple disciplines that are missing in the integrated approach (Brophy et al., 2008; Estapa and Tank, 2017; Moore et al., 2014; Wendell and Rogers, 2013).

In this study, we used a STEM system as a tool and the materials for the physics learning process. We considered the engineering viewpoint as we employed a soundcard oscilloscope software on the student's personal computer (Hasanah et al., 2017). This software was supplemented by additional STEM materials to reduce the participating Indonesian secondary school student's misconceptions in the AC circuit topics. To this end, the researchers investigated the following research questions:

1. What are the existing misconceptions about AC topics for Indonesian secondary school's student case? How effective is the develop AC circuit in overcoming student's misconceptions?

2. Is there any significant difference between the understanding level of students in both the control and experimental groups?

In this study, the Indonesian misconceptions that were found in the preliminary survey were to be addressed through the STEM system. Further, how effective the STEM system within an engineering context was in overcoming these misconceptions will be discussed.

\section{METHODOLOGY}

This study was a multimethod research study with three phases. The first and second phases were applied to answer the first research question and the last phase for the second research question. In the beginning, we tried to develop a STEM system in the AC circuit. It was prepared by the following methodology that was adapted from Wendell and Rogers (2013); (1) acquire relevant knowledge of the topic, (2) conduct several experiments using different materials, (3) design apparatus, (4) fabricate the apparatus in the laboratories of Hiroshima University, (5) conduct the experiments using the fabricated apparatus with soundcard oscilloscope, (6) collect, compile, and analyze the data, and (7) bring the fixed teaching material to the real class.

The STEM system involved a stereo capture device and cable connections, probes, a voltage divider, a circuit plate, $R L C$ components, multimeter, and a laptop computer as a soundcard oscilloscope with a signal generator, as shown in Figure 1.

\section{Stereo Capture and Cable Connection}

Audio cable connection was one point two as a positive and negative with diameter $3.5 \mathrm{~mm}$ and length $1.8 \mathrm{~m}$ which was produced by TFTEC Japan. We changed the face of positive and negative using crocodile clips. The stereo capture interface was to be used for any laptop computer which did not have a stereo port or only had a mono audio port.

\section{Probe}

Oscilloscope probe used audio cable with a $3.5 \mathrm{~mm}$ diameter and a $1.8 \mathrm{~cm}$ length and had four branches. Crocodile clips were used so that it could be used in the circuit.

\section{Voltage Divider}

This voltage divider used OP amplifier LM358N, two capacitors $100 \mu \mathrm{F}$, two capacitors $10 \times 10^{4} \mathrm{pF}$, two resistors one $\mathrm{k} \Omega$, two resistors $1 \mathrm{M} \Omega$, and adaptor 9 volts. This interface circuit was a filter for the high voltage to allow our laptop computer soundcard to be used safely.

\section{RLC Component}

This involved three components; resistor, inductor, and capacitor. Each component had their value, we chose five resistances for the resistor; $62.3 \Omega ; 82 \Omega ; 100 \Omega ; 268 \Omega$; and $619 \Omega$, it used five values for inductor; $2.2 \mathrm{mH} ; 4.7 \mathrm{mH}$; $4.8 \mathrm{mH} ; 6 \mathrm{mH}$; and $20 \mathrm{mH}$, we picked only two capacitances; $20 \mathrm{nF}$ and $40 \mathrm{nF}$. All components were used for a circuit that we wanted to measure from a single circuit until the series $R L C$ circuit. In the case of frequency response experiment, we utilized three resistors ( $20 \Omega, 40 \Omega$, and $60 \Omega$ ), inductor $0.051 \mathrm{H}$, and capacitor $0.334 \mu \mathrm{F}$.

\section{Soundcard Oscilloscope}

The display of software was arranged just like a conventional oscilloscope with the frequency analysis functionality and signal generator, as shown in Figure 2. This soundcard oscilloscope could be used for many kinds of measurements. For example, the previous researchers have used it to measure the relationship between frequency and the amplitude of the voltage signal (Wild et al., 2010). In addition, the soundcard oscilloscope was free for public education purposes (Wild and Swan, 2011; Zeitnit, 2015). Hence, this software oscilloscope 


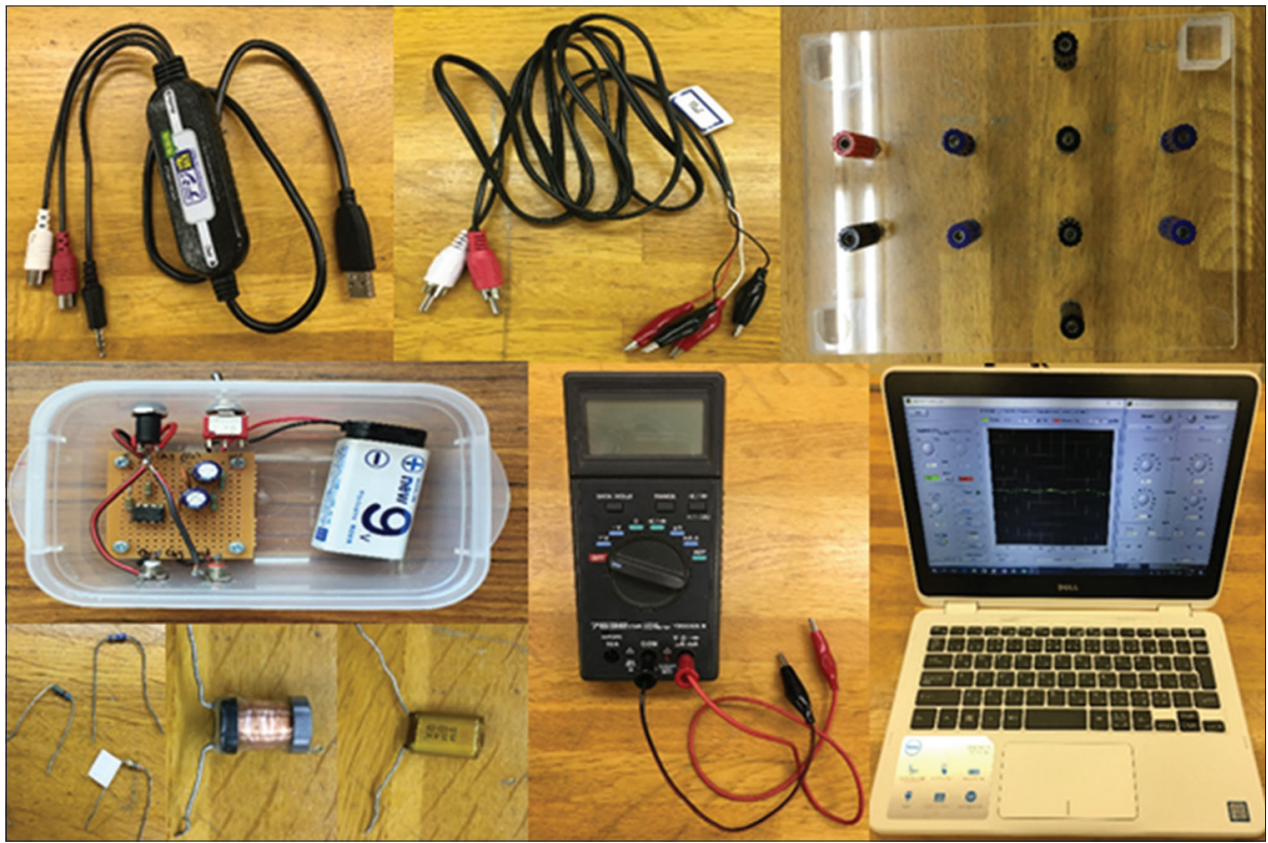

Figure 1: Experimental apparatus for the alternating current circuit using science, technology, engineering, and mathematics teaching material

was organized with additional low-priced apparatus (Figure 3) addressing the lack of experimental apparatus in Indonesia.

Since the oscilloscope was one of the critical engineering tools to check the electrical circuit, the developed experimental apparatus was sufficient to undertake experiments with AC circuits considering the engineering framework of STEM education. Engineering is a natural integrator to support the learning science. Table 1 shows the four indicators that were adopted for this study. In general, there are nine key indicators in the engineering framework, but we used only engineering thinking, engineering tools, teamwork, and engineering communication due to the scope of the indicator from competency achievement in Indonesia as well as time limitations. In this learning process, students were divided into five teams for each class and become independent thinkers who decide the material in their experiments such as the resistance, capacitance, and inductance. Hence, they could observe the effect of the variable through the software oscilloscope. Students analyzed the sinusoidal wave and inputted the data into Excel to find the relationship among variables; those activities were named engineering skills.

Meanwhile, the content in the learning process was based on the indicators from the basic competence of the Indonesian curriculum for senior high school Grade 12 (MoEC, 2015), as follows:

\section{Basic Competence}

"Formulating the Faraday's Law of induction concept, AC, and the implementation."

\section{Indicators}

1. Understanding the AC sources, phasor diagram, a graph of voltage and current as a function of time in the $\mathrm{AC}$ circuit,

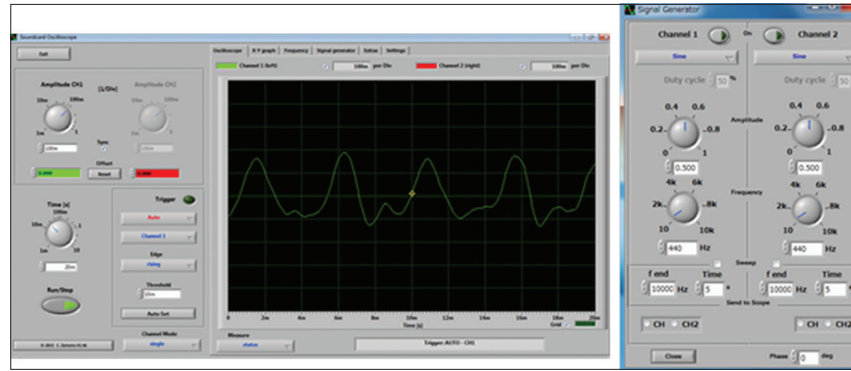

Figure 2: Soundcard oscilloscope and signal generator

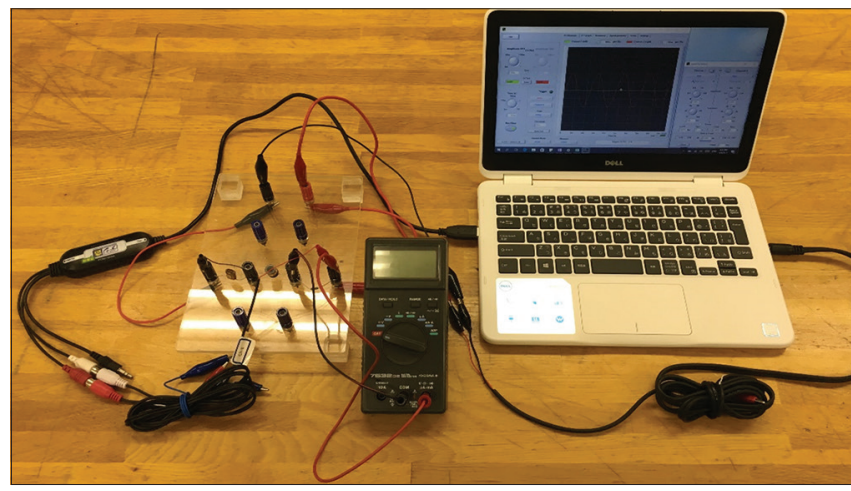

Figure 3: Example of the alternating current circuit experiment using soundcard oscilloscope

2. Understanding the concept of sinusoidal waveform voltage and current in $R, L, C, R L, R C$, and $R L C$ circuits,

3. Understanding the relationships between frequency and reactance in $R, L, C, R L, R C$, and $R L C$ circuits

4. Formulating and determining reactance and impedance of $R C, R L$, and $R L C$ circuits. 
The second phase was a review of previous studies concerning existing misconceptions that may happen in AC topics. We found two articles, both were quantitative research (Biswas et al., 1998; Posner et al., 1982). In this study, the misconceptions are related to voltage, current, power source, the effect of the function of a component at the point in time, as well as the characteristics of $\mathrm{AC}$ waveforms, as indicated in Table 2. Those misconceptions were used as the basis of our measurement for the Indonesian case. It was taken based on the four indicators in $\mathrm{AC}$ topics for the secondary level in Indonesia.

\begin{tabular}{lc}
\hline $\begin{array}{l}\text { Table 1: The framework for quality } \\
\text { education }\end{array}$ & Adapted indicators \\
\hline Key indicators & \\
\hline $\begin{array}{l}\text { Processes of design } \\
\text { Apply science, engineering, and mathematics }\end{array}$ & $\sqrt{ }$ \\
$\begin{array}{l}\text { Engineering thinking } \\
\text { Conceptions of engineers and engineering }\end{array}$ & $\sqrt{ }$ \\
$\begin{array}{l}\text { Engineering tools } \\
\text { Issues, solutions, and impacts }\end{array}$ \\
$\begin{array}{l}\text { Ethics } \\
\text { Teamwork }\end{array}$ \\
Communication related to engineering & $\sqrt{ }$ \\
\hline
\end{tabular}

(Taken from Moore et al., 2014)
The 13 adapted instruments were developed as a conceptual understanding test question in two-tier multiple choice for the misconception's analysis (Biswas et al., 1998; Posner et al., 1982). Each item has five choices and blank space for reasoning. All of the participants should include their reasoning to help reviewers identifying the concept within each of the items.

The last phase was identifying the misconception in Indonesia that focuses as pre-experimental research design. A total of 192 students were selected as the participants. They came from eight classes in Grade 12 and two secondary schools in South Sulawesi, Indonesia. The students were located in one class by their school administrator randomly that confirmed the homogeneity. Then, we divided those classes into two groups as the control and the experimental groups, so each group consisted of four classes with 96 students. The control group was taught by a conventional learning method. Meanwhile, the experimental group was taught by the STEM system. Then, this study was conducted in a 4-week intervention for the implementation of the STEM system and also the conventional learning. The differences between these groups are described through the comparison of the lesson plan in Table 3.

The descriptive statistics were applied to find student's misconceptions by analyzing their answers. The adapted rubric was adjusted from Kucukozer and Kocakulah (2007) which is described in Table 4.

\section{Table 2: Type of misconceptions}

\begin{tabular}{lll}
\hline Type of misconceptions & Identified misconception & Author \\
\hline $\begin{array}{l}\text { 1.Spatial misconception } \\
\text { 2.Inability to recognize the differences } \\
\text { between voltage and current and the belief } \\
\text { that current remained constant in a circuit }\end{array}$ & $\begin{array}{l}\text { Because students think that the sinusoidal AC, voltage, and } \\
\text { current waveforms are not a representation of the variation } \\
\text { of these variables at a point in time } \\
\text { Because students think that voltage and current that were } \\
\text { shown by a sinusoidal wave in any circuit are similar }\end{array}$ \\
$\begin{array}{l}\text { 3.Inability to recognize the effect of changing } \\
\text { source frequency on power consumed in a } \\
\text { circuit }\end{array}$ & $\begin{array}{l}\text { Because students think that frequency does not have any } \\
\text { influence in the alternating current circuit }\end{array}$ \\
$\begin{array}{l}\text { 4.Resistance and equivalent resistance } \\
\text { (impedance) }\end{array}$ & $\begin{array}{l}\text { Because students think that if the number of resistances } \\
\text { increases in a circuit, equivalent resistance also increases } \\
\text { as independent from their connection type }\end{array}$ \\
\hline
\end{tabular}

\section{Table 3: Comparison between lesson plan both groups}

\begin{tabular}{lc}
\hline Experimental group & Control group \\
\hline Introduction & Introduction \\
Asking for some key questions which are related to today's topic & Main part \\
Main part & The teacher explains about alternating current \\
The teacher starts to stimulate the idea of the students & Giving questions which are related to the \\
For example: Showing the example of the sinusoidal wave to the students through simple resistor & equation and let the students answer it \\
circuit (demonstrate), then the teacher can let students conduct an experiment and what will happen if & \\
you change the resistance with constant frequency. & Conclusion \\
Planning the hypothesis (conducted by students) & No conclusion, no feedback \\
Experiment (conducted by students) & \\
Conclusion &
\end{tabular}


Figure 4 shows how responses were analyzed. This flowchart highlights the branches resulting for how the students reported the required definition of scientifically complete response and the classification explanations in specific categories (Driver and Erickson, 1983; Kabapinar, 1998).

\begin{tabular}{|c|c|c|}
\hline Level & Type of response & Categories \\
\hline $\mathrm{A}$ & Correct answer + correct reason & Fully understanding \\
\hline $\mathrm{B}$ & Correct answer + incorrect reason & Partially understanding \\
\hline $\mathrm{C}$ & $\begin{array}{l}\text { Incorrect answer }+ \text { incorrect reason } \\
\text { which is the reason based on the } \\
\text { cause of the incorrect answer or } \\
\text { related to the chosen answer }\end{array}$ & Misconception \\
\hline $\mathrm{D}$ & $\begin{array}{l}\text { Incorrect answer }+ \text { incorrect reason } \\
\text { which the reason is not related to the } \\
\text { chosen answer }\end{array}$ & Lack of understanding \\
\hline
\end{tabular}

The flowchart then terminates in the classification rubric of Table 4. In the end, the descriptive statistics were functioned to summarize the answer of students in the misconception level by analyzing the most selected answers as well as the reason to find the alternative concept. In the inferential statistics, the Chi-square test was employed to prove the difference between the understanding level of students in both groups. In the Chi-square test, the SPSS software 20 was used to analyze all data.

\section{RESULTS AND DISCUSSION}

In this section, we explain the misconceptions for each indicator that was found as the result of the descriptive statistics. The explanations below will also show how effective the STEM system work was in reducing the misconceptions of the students in AC topics.

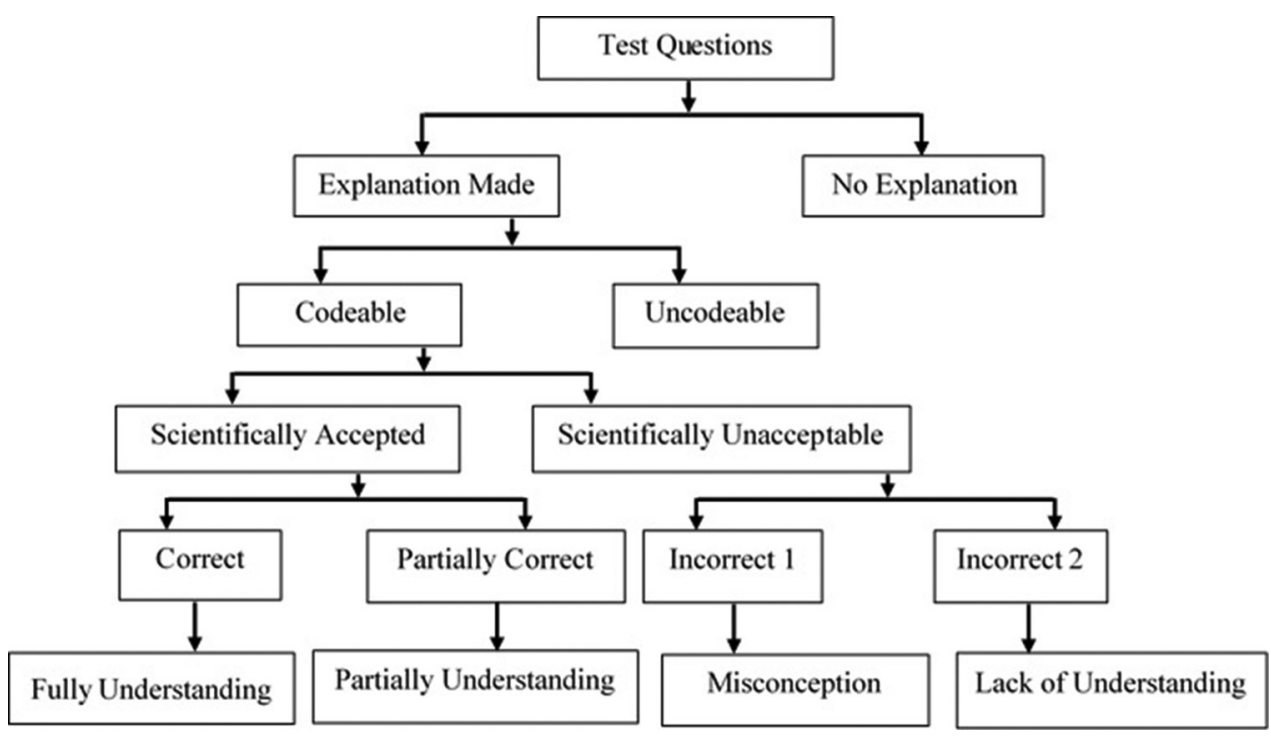

Figure 4: Analysis of conceptual understanding test questions

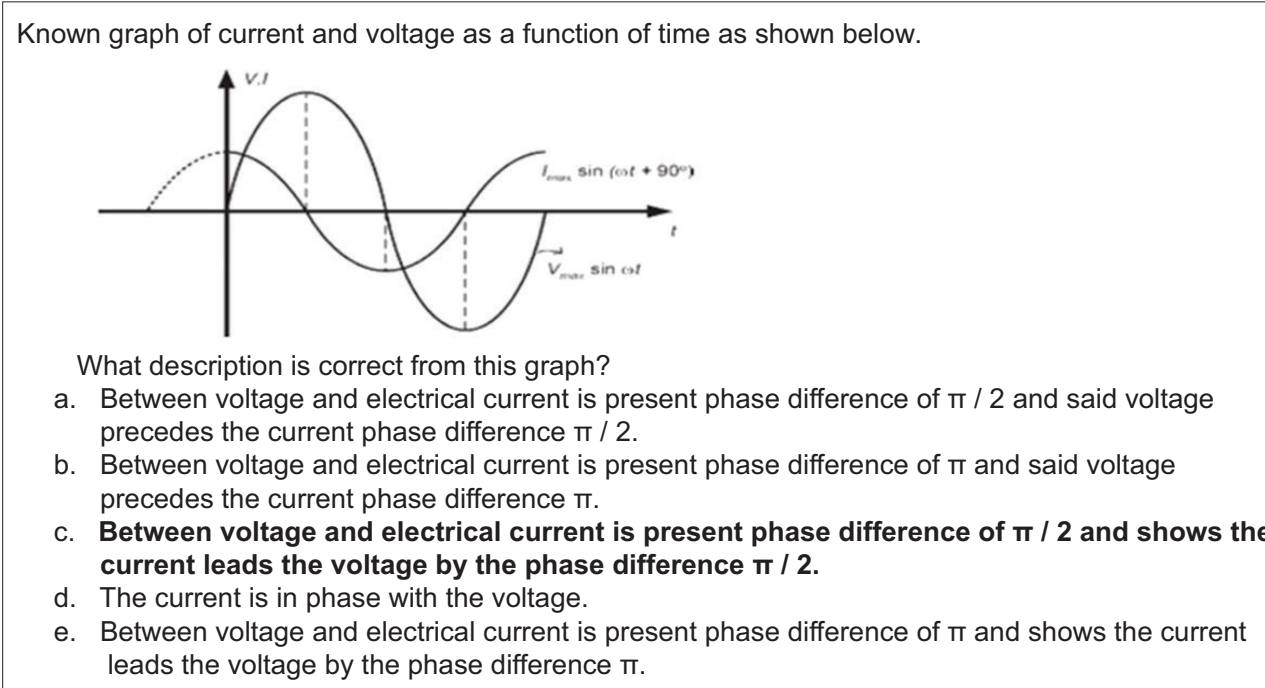

Figure 5: Item number 1 


\section{1st: Misinterpreted the Graph between Voltage and Current}

The first indicator included the question numbers 1 and 2, but we will go further with item number 1 in Figure 5 to see how the STEM system influenced the concept of the students. Those questions were related to $\mathrm{AC}$ sources, phasor diagrams, and a graph of voltage and current as a function of time in the $\mathrm{AC}$ circuit. We attempted to address whether or not students had a great understanding of current and voltage as a function of time through sinusoidal wave in the display of oscilloscope as we mention in Figure 5.

As known, in the sinusoidal wave, one cycle (the phase angle is $\left.360^{\circ}\right)$ consists of one hill as positive half $\left(180^{\circ}=\pi\right)$ and one valley as negative half $\left(180^{\circ}=\pi\right)$. Through the graph, both groups of students could observe that the sine wave of current precedes the sine wave of voltage as a half of one hill which means $180^{\circ} / 2$ or $\pi / 2$. In the learning process, the experiment was conducted to show what the difference of phase between voltage and current as a shift of wave indicated in the graph. One of the analogies used was the symbol and also the color of the wave so they could recognize current and voltage more easily.

In the experimental group, students could spontaneously answer with the correct reason. They described that the voltage and electrical current had a phase difference of $\pi / 2$ and showed the current leads the voltage by the phase difference $\pi / 2$. It was because they could read and had a great understanding of the symbol also the hill and valley without depending on the wave color. In Table 5, item 1 reports on the different levels of understanding of both groups, it also shows that misconception level in the control group was higher than the experimental group with a total frequency of 76 students. Those reasons revealed that students believe that " $I_{\max } \sin \left(\omega t+90^{\circ}\right)$ " was voltage and " $V_{\max } \sin \omega t$ " was current.

The most frequent answer that came as an alternative concept (i.e., misconception) was "Because the picture shows that voltage precedes current with phase difference $\pi$." Hence, these students misinterpreted the graph in the question; the amount of student in this first indicator still could not read the graph correctly as a function of time using a different symbol.
It shows the difficulty of the students to catch the similarity of the experimental concept and theoretical knowledge. In the experimental group, students observed the wave as a function of time in "second," not in " $\pi$." This also might have happened because students got used to seeing the graph with symbol supported by the wave color. Contrary, we used an illustration graph without coloring in the question where students must differentiate the wave by themselves.

\section{$2^{\text {nd: }}$ Difficulty Thinking of Phenomena because the Student Cannot See the Existence of a Magnetic Field; Student Unrecognized the Characteristic in AC Simple Circuit}

The second indicator focuses on the concept of sinusoidal waveform voltage and current for RLC circuit that was measured by question numbers 3 and 4 . Item number 3 is shown in Figure 6. Students should understand the circuit which consists of a pure inductance of $L$; it was linked across a sinusoidal voltage given by $V(t)=V_{\max } \sin \omega t$. When the adjustment is closed, this sinusoidal voltage will cause a current movement and rise from zero to its maximum value as the impact of the magnetic field.

In this part, we expected the students to realize the phenomena of the rise or change in the current about a magnetic field within the coil. It would produce the opposed or restricted current to prevent the magnetic field change. However, before the current reaches its maximum value, the voltage changes its polarity; the current flow changes its direction. This change of current in the opposite direction is delayed $90^{\circ}$ by the self-induced back emf in the coil; the circuit contains a pure inductance only. Students found difficulty in applying the concept.

Item 2 in Table 5 describes the result of the third indicator. The misconception was still the most dominant level; the frequency

What is happened to the voltage and the current in inductive $L$ circuit?

a. Phase voltage $\vee$ preceded phase current by $\varphi=90^{\circ}$.

b. There is no phase difference between voltage and current.

c. Phase voltage $v$ preceded phase current I by $C=45^{\circ}$

d. Phase voltage $v$ lag phase current i by $\omega=90^{\circ}$

e. Phase voltage $v$ lag phase current I by $\omega=45^{\circ}$

Figure 6: Item number 3

\section{Table 5: Results of survey for each misconception}

\begin{tabular}{|c|c|c|c|c|c|c|c|c|}
\hline \multirow[t]{2}{*}{ No. } & \multirow[t]{2}{*}{ Misconception } & \multirow[t]{2}{*}{ Group } & \multicolumn{4}{|c|}{$\begin{array}{l}\text { Level of responses' } \\
\text { frequency }\end{array}$} & \multirow[t]{2}{*}{ Total } & \multirow[t]{2}{*}{ p-value } \\
\hline & & & A & B & C & D & & \\
\hline \multirow[t]{2}{*}{1.} & \multirow{2}{*}{$\begin{array}{l}\text { The picture shows that voltage precedes current with phase difference } \pi \text { or } \pi / 2 \text {. Students } \\
\text { misinterpret the graph }\end{array}$} & Cont. & 0 & 37 & 44 & 15 & 96 & $<0.01$ \\
\hline & & Exp. & 41 & 19 & 32 & 4 & 96 & \\
\hline \multirow[t]{2}{*}{2.} & \multirow{2}{*}{$\begin{array}{l}\text { The magnetic field within the coil does not have an impact on the current. Students cannot } \\
\text { see the existence of a magnetic field }\end{array}$} & Cont. & 0 & 19 & 47 & 30 & 96 & $<0.01$ \\
\hline & & Exp. & 14 & 26 & 36 & 20 & 96 & \\
\hline \multirow[t]{2}{*}{3.} & \multirow[t]{2}{*}{ Capacitance does not influence the capacitive reactance, only frequency } & Cont. & 11 & 17 & 41 & 27 & 96 & $<0.01$ \\
\hline & & Exp. & 28 & 40 & 20 & 8 & 96 & \\
\hline \multirow[t]{3}{*}{4.} & \multirow[t]{3}{*}{ Voltmeter and ammeter can measure only maximum value in the alternating current circuit } & Cont. & 5 & 16 & 41 & 34 & 96 & $<0.01$ \\
\hline & & Exp. & 35 & 18 & 12 & 31 & 96 & \\
\hline & & & 134 & 192 & 273 & 169 & & \\
\hline
\end{tabular}




$$
\begin{aligned}
& \text { What statement is correct which describe relation among frequency, capacitance and capacitive } \\
& \text { reactance in } \mathrm{AC} \text { circuit! } \\
& \text { a. The higher the frequency of the alternating current through a capacitor, the greater the } \\
& \text { capacitive reactance. } \\
& \text { b. The higher the frequency of alternating current through a capacitor, the smallest the } \\
& \text { capacitive reactance } \\
& \text { c. The higher the capacitance of alternating current through a capacitor, the greater capacitive } \\
& \text { d. Capacitance do not have influence on the capacitive capacitance, only frequency. } \\
& \text { e. Frequency do not have influence on the capacitive reactance. }
\end{aligned}
$$

Figure 7: Item number 4

between the experimental and control groups slightly decreased from 47 to 36 and totaled 83 students. It shows that some students could not avoid the misconception in the concept of magnetic field before utilizing the developed STEM system. From the students' answer, it was found that the most frequent answer in the misconception level was "Because of Current lags voltage by $\pi / 2$." In this case, students thought that the magnetic field within the coil did not have an impact on the current; it did not oppose or restrict the change in the current. They believed that only voltage and current could influence each other because they could not observe the magnetic field by themselves.

\section{$3^{\text {rd: }}$ : Misunderstanding the Relationship among Frequency, Amplitude, and Resistance in the Case of Theoretical and Experiments}

In this indicator, three questions were provided to observe the existing misconceptions in the relationship among frequency, capacitance, and capacitive reactance in the AC circuit. The capacitive reactance $(X \mathrm{c})$ is inversely proportional to frequency $(f)$ indicated in the formula " $X_{\mathrm{C}}=\frac{1}{\omega C}=\frac{1}{2 \pi f C}$." We took question number 6 that required students in experimental group to connect the theoretical knowledge with their experiments using the relationship between frequency and reactance for each component.

This result revealed that the misconception level could be solved in the experimental group, i.e., with the STEM system. Moreover, as we observed both the control and experimental group in this indicator dominant in the different levels. The control group was in the misconception level with 41 students, while the experimental group was in the partially understanding level with 40 students. The result of this indicator is shown in item 3, Table 5, with a cumulative frequency of 61 students in the misconception level. Students tended to answer that "The higher frequency creates, the greater capacitive reactance;" the most frequent reason from the students was "Because capacitance does not influence the capacitive reactance." Students could not realize the function of the capacitor as well as the frequency which influenced the capacitive reactance; they misunderstood the relationship among frequency, amplitude, and resistance (Figure 7).

\section{$4^{\text {th: }}$ : Resistance and Equivalent Resistance (Impedance)} Three representative instruments for the fourth indicator talk about how the circuit system works for the resonance

What will be happened if in An RLC circuit Inductive reactance equal
capacitive reactance?
a. Recharging
b. Maximum power transfer
c. Block low-frequency signals
d. Resonance phenomena

Figure 8: Item number 9

phenomena and what is the impedance in an AC circuit. The fourth misconception, we took item number 9 that is shown in Figure 8 as a representative that examined the characteristic of resonance phenomena and understanding the concept based on the experiment.

In the experimental group, students were mostly in the fully understanding level, as shown in Table 5, item 4. However, 12 students had a misconception; the total of the students who had misconceptions in both groups was 53. The most frequent answer was maximum power transfer with reasoning "in the $R L C$ circuit if the inductive reactance is similar to the capacitive one, there is no resistance because of the equality for voltage and current; the maximum power transfer takes place." When the inductive reactance is equal to the capacitive, $X_{\mathrm{L}}=X_{\mathrm{C}}$, the phase angle $\varphi$ is zero; the impedance of the circuit is equivalent to pure resistance, i.e., $Z=R$. In this case, the voltage and current were in phase with the so-called resistive circuits; the capacitive one canceled the inductive nature. Hence, the resistive state with maximum current was called a resonance phenomenon.

From the results, it was considered that students were still unable to realize the resonance phenomenon in the $R L C$ circuit. They used their own experiences from their daily life. For instance, students tended to imagine that the two reactances negated each other; there would be nothing to resist the current and voltage. Hence, the maximum electric power would be transferred through the circuit.

As a result, we could conclude how the STEM system still had a limitation in case of some phenomena in AC topics, especially in the second and fourth misconceptions which are a kind of real phenomena that still cannot be caught by students using this developed AC circuit.

Furthermore, these misconceptions that emerged for each indicator in the Indonesian case were quite similar compared to the previous study (Biswas et al., 1998; Posner et al., 1982), but 
the frequency for the entire level of understanding confirmed the effectiveness of STEM system. Based on the Chi-square test in the SPSS output, the Pearson Chi-square significance level (p-value) was computed to be smaller than 0.01 , which is less than the alpha level of the significance 0.05 , confirmed that it was significantly different between the understanding level of students in both control and experimental groups.

\section{CONCLUSIONS AND RECOMMENDATIONS}

This study aimed to investigate how effective was the study's STEM system that focused on an engineering context in overcoming students' misconceptions. The finding of this study has shown that the regards to the first research question; four misconceptions still existed after the treatment. The second research question also confirmed that there was a significant difference in the students understanding between the control and experimental groups. This difference was caused by the developed STEM system which included an engineering viewpoint of AC circuit topics.

Students' concepts and understanding of physical phenomena and mathematical formulation significantly affected the students' achievement and their final conceptions. Students in the control group showed the tendency to be located in the understanding and misconception level for all indicators. Meanwhile, students in the experimental group, in which the STEM system was applied, were predominantly located in the fully understanding and partially understanding level. However, the difficulties of differentiating the voltage and current, understanding the function of each component, as well as connecting the theoretical part to the experimental part were identified as the most significant parts for students in both groups.

Furthermore, students' activity through the experiment using the STEM system required the students to find other information related to what they had learned through reading the textbook and the other sources. It was an unsolved issue until this study because teachers had limitations in being able to ensure students' activity outside the school. Since STEM education has engineering viewpoints, the STEM system for the physical phenomena like electromagnetics was considered to be useful to overcome the various misconceptions in high school physics.

In physics, one system has a probability to fix or unfix with one concept. More researchers should find or create, develop, and try more teaching material that can support the understanding of students in AC circuits as well as the other parts of physics. Meanwhile, physics depends on the student's pre-concept. Researchers cannot avoid this as it impacts on student's misconception. Finding out the pre-concept for each concept that researchers are looking for students should be one of the main focuses of the other researchers investigating cases of misconception.

\section{Limitation of the Study}

In this research, the data were taken as much as we could, but a lack of some crucial parts still exists. First, the STEM system that was applied in this study addressed one of the most difficult theories in secondary school physics as the starting point, we still have difficulty implementing another STEM system in physics. Time limitations for experimenting as well as interviews also had a significant impact on this research; we obtained 28 students' responses related to the STEM system and the assessment. Hence, enough feedbacks from students about the developed apparatus as well as the deeper reasons for misconceptions could not be found. In addition, we found some similarities between the control and experimental groups. The survey results explained that the number of students for "lack of understanding level" still showed a big number. In this case, students could record a choice even if they did not understand or did not know the answer to the question (i.e., guessing). This may have been impacted results relating to "partially understanding level" as the frequency for that level was quite high compared to the other levels. Students who randomly answered without knowing were detected. Hence, such kind of two-tier multiple choice limits the generalizability of the results to the wider population.

\section{ACKNOWLEDGMENTS}

This work was supported by Indonesia Endowment Fund for Education Scholarship (LPDP) and the grant-in-aid for scientific research (A) (No. 17H00820) from the Japan Society for the Promotion of Science.

\section{REFERENCES}

Biswas, G., Schwart, D., Bhuva, B., Bransford, J., Brophy, S., Balac, T., \& Kattzlberger, T. (1998). Analysis of Student Understanding of Basic AC Concepts. Nashville: Vanderbilt University. p1-32.

Brophy, S., Klein, S., Portsmore, M., \& Rogers, C. (2008). Advancing engineering education in P-12 classroom. Journal of Engineering Education, 97(3), 369-387.

Caliskan, S., Selcuk, G.S., \& Erol, M. (2010). Effects of the problem solving strategies instruction on the students' physics problem solving performances and strategy usage. Procedia Social and Behavioral Sciences, 2, 2239-2243.

Chong, C.D., Salleh, S.M., \& AiCheong, I.P. (2013). Using an activity worksheet to remediate students' alternative conceptions of metallic bonding. American International Journal of Contemporary Research, 11(3), 39-52.

Djamal, M. (2013). Physics Education in Indonesia. Available from: https:// www.jps.or.jp/ASEPS3RT3\&4/RT4_Djamal_ASEPS3.pdf. [Last accessed on 2020 Feb 12].

Driver, R., \& Erickson, G. (1983). Theories-in action; some theoritical and empirical issues in the study of students' conceptual frameworks in science. Studies in Science Education, 10, 37-60.

Duit, R., Jung, W., Rhöneck, V.C. (1985). Aspects of Understanding Electricity: Proceedings of an International Workshop: An Inventory of Research Results Concerning the Representation of Students' Knowledge of Electricity and its Uses for the Improvement of Teaching. Ludwigsburg, September 10 to 14, 1984. Institute for Science Education at the University of Kiel, Kiel.

Essays. (2018). The National Curriculum of Indonesia and its Changes. https://www.ukessays.com/essays/education/the-national-curriculumof-indonesia-and-its-changes-education-essay.php?vref $=1 . \quad$ [Last accessed on 2020 Jan 22].

Estapa, A.T., \& Tank, K.M. (2017). Supporting integrated STEM in the elementary classroom: A professional development approach centered on an engineering design challenge. International Journal of STEM 
Education, 4(6), 2-16.

Hasanah, U., Massango, H., Tsutaoka, T., \& Shimizu, K. (2017). A teaching material for learning alternating current circuit using soundcard oscilloscope experiments for the electrical resonance. Unnes Science Education Journal, 6(2), 1606-1611.

Honey, M., Pearson, G., \& Schweingruber, H. (2014). STEM Integration in K-12 Education: Status, Prospects, and an Agenda for Research. Available from: https://www.pdfs.semanticscholar.org/ bac5/69ca108d7ac7c96574826419074316150060.pdf. [Last accessed on 2020 Jan 22].

Kabapinar, F. (1998). Teaching for Conceptual Understanding; Developing and Evaluating Turkish Students Understanding of the Solubility Concept through a Specific Teaching Intervention. (Unpublished Ph.D Dissertation. School of Education. England: The University of Leeds.

Kolodner, J.L., Camp, P.J., Crismond, D., Fasse, B., Gray, J., Holbrook, J., \& Ryan, M. (2003). Problem-based learning meets case-based reasoning in the middle-school science classroom: Putting learning by design ${ }^{\mathrm{TM}}$ into practice. Journal of the Learning Sciences, 12(4), 495-547.

Kucukozer, H., \& Kocakulah, S. (2007). Secondary school students' misconceptions about simple electric circuits. Journal of Turkish Science Education, 4, 101-115.

Leonard, W.J., Dufresne, R.J., \& Mestre, J.P. (1996). Using qualitative problem-solving strategies to highlight the role of conceptual knowledge in solving problems. American Journal of Physics, 64, 1495-1503.

Marini, A. (2017). Character building through teaching learning process: Lesson in Indonesia. International Journal of Sciences and Research, 73(5), 177-182.

Moore, T.J., Glancy, A.W., Tank, K.M., Kersten, J.A., \& Smith, K.A. (2014). A Framework for quality K-12 engineering education; research and development. Journal of Pre-College Engineering Education Research, 4(1), 1-13.

Moore, T.J., Stohlmann, M.S., Wang, H.H., Tank, K.M., Glancy, A.W., \& Roehrig, G.H. (2014). Implementation and integration of engineering in K-12 STEM education. In: Strobel, J., Purzer, S., \& Cardella, M. (Eds.), Engineering in Precollege Settings: Research into Practice. Rotterdam, The Netherlands: Sense Publishers. p35-60.

Posner, G.J., Strike, K.A., Hewson, P.W., \& Gertzog, W.A. (1982). Accommodation of scientific conception: Toward a theory of conceptual change. Science Education, 66(16), 211-227.
Putri, L.O.L., Rahman, T., \& Priyandoko, D. (2017). Analyzing concepts mastery and misconceptions about evaluation of biology major students. Conference Series: Journal of Physics, 7, 1-6.

Quang, L.X., Hoang, L.H., Chuan, V.D., Nam, N.H., Anh, N.T.T., \& Nhung, V.T.H. (2015). Integrated science, technology, engineering and mathematics (STEM education through active experience of designing technical toys in Vietnamese schools. British Journal of Education, Society and Behavioral Science, 11(2), 1-12.

Sadi, O., \& Cakiroglu, J. (2011). Effects of hands-on activity enriched instruction on students' achievement and attitudes towards science. Journal of Baltic Science Education, 10(2), 87-97.

Shipstone, D.M., Rhoneck, C.V., Jung, W., Karrqvist, C., Dupin, J.J., Joshua, S., \& Licht, P. (1988). A study of secondary students' understanding of electricity in five European countries. International Journal of Science Education, 10, 303-316.

Smith, E.L., Blakeslee, T.D., \& Anderson, C.W. (1993). Teaching strategies associated with conceptual change learning in science. Journal of Research in Science Teaching, 30(2), 111-126.

Susilowati, A. (2006). Difficulty profile of physics focused in electricity for Secondary School students in Semarang. [Profil kelistrikan belajar fisika pokok bahasan kelistrikan siswa SMA di Kota Semarang]. Jurnal Pendidikan Fisika Indonesia, 4(2), 100-106.

Sutherland, L. (2002). Developing problem solving expertise: The impact of instruction in a question analysis strategy. Learning and Instruction, 12(2), 155-187.

Turgut, U., Gurbuz, F., \& Turgut, G. (2011). An investigation $10^{\text {th }}$ grade students' misconceptions about electric current. Procedia Social and Behavioral Sciences, 12, 1965-1971.

Wendell, K.B., \& Rogers, C. (2013). Engineering design-based science, science content performance, and science attitudes in elementary school. Journal of Engineering Education, 102(4), 513-540.

Wild, G., \& Swan, G. (2011). The development of acoustic experiments for off-campus teaching and learning. Physics Education, 46(3), 281-289.

Wild, G., Swan, G., \& Hinkley, S. (2010). AC Electricity Experiments for off-Campus Teaching and Learning. Available from: https://www. researchgate.net/publication/254591948_ac_electricity_experiments for_off-campus_teaching_and_learning. [Last accessed on 2020 Jan 22].

Zeitnitz, C. (2015). Manual for the Sound Card Oscilloscope V1.46. Available from: http://www.zeitnitz.eu/scope en. [Last accessed on 2020 Jan 22]. 